\title{
Formoterol as relief medication in asthma: a worldwide safety and effectiveness trial
}

\author{
R.A. Pauwels*, M.R. Sears\#, M. Campbell ${ }^{\star}$, C. Villasante ${ }^{+}$, S. Huang ${ }^{\S}$, A. Lindh ${ }^{f}$, W. Petermann**, \\ M. Aubier ${ }^{\# \#}$, G. Schwabe ${ }^{\uparrow}$, T. Bengtsson ${ }^{\uparrow}$, on behalf of the RELIEF Study investigators
}

Formoterol as relief medication in asthma: a worldwide safety and effectiveness trial. R.A. Pauwels, M.R. Sears, M. Campbell, C. Villasante, S. Huang, A. Lindh, W. Petermann, M. Aubier, G. Schwabe, T. Bengtsson. (C) ERS Journals Ltd 2003.

ABSTRACT: The aim of the study was to compare the safety and effectiveness of asneeded formoterol with salbutamol in a large international real-life asthma study.

Children and adults $(n=18,124)$ were randomised to 6 months as-needed treatment with open-label formoterol $4.5 \mu \mathrm{g}$ Turbuhaler $\AA$ or salbutamol $200 \mu \mathrm{g}$ pressurised metered dose inhaler or equivalent. Primary safety variables were asthma-related and nonasthma-related serious adverse events (SAE)s and adverse events (AE)s resulting in discontinuation (DAE)s. The primary efficacy variable was time to first asthma exacerbation.

The incidences of AEs, SAEs and DAEs arising from SAEs were not significantly different between treatments. DAEs for nonserious AEs were higher with formoterol. Asthma-related AEs decreased with formoterol (1,098 (12.3\%) versus 1,206 (13.5\%)), asthma-related SAEs were similar $(108(1.2 \%)$ versus $121(1.4 \%))$ but more asthmarelated DAEs occurred in the formoterol group $(89(1.0 \%)$ versus $48(0.5 \%))$. Time to first exacerbation was prolonged (hazard ratio 0.86 ) and less as-needed and maintenance medication was used with formoterol. Reductions of exacerbations with as-needed formoterol versus salbutamol increased with increasing age and asthma medication level.

This real-life study demonstrates that formoterol as-needed has a similar safety profile to salbutamol, and its use as a reliever therapy is associated with fewer asthma symptoms and exacerbations.

Eur Respir J 2003; 22: 787-794.
*Dept of Respiratory Diseases, Ghent University Hospital, Ghent, Belgium, ${ }^{\#}$ Firestone Institute for Respiratory Health, St. Joseph's Healthcare and McMaster University, Hamilton, Canada, Dept of General Practice, University of Glasgow, Glasgow, UK, ${ }^{+}$Dept of Respiratory Diseases, Hospital Universitario La Paz, Madrid, Spain, ${ }^{\$}$ Pulmonary Dept, Rui Jin Hospital, Shanghai Second Medical University, Shanghai, China, ${ }^{f}$ Husläkarna Österåker, Åkersberga, Sweden, ${ }^{* *}$ Dept of Internal Medicine. Brüderkrankenhaus, Paderborn, Germany, \#\# Dept of Pneumology, Hôpital Bichat Claude Bernard, Paris, France and Clinical Development, AstraZeneca R\&D Lund, Lund, Sweden.

Correspondence: R. Pauwels, Dept of Respiratory Diseases, University Hospital, De Pintelaan 185, B9000 Ghent, Belgium.

Fax: 3292402341

E-mail: Romain.Pauwels@UGent.be

Keywords: Age, asthma, effectiveness, formoterol, safety, salbutamol

Received: May 192003

Accepted: August 72003
Guidelines for treatment of asthma recommend regular use of anti-inflammatory therapy for any form of persistent asthma and a minimal use of reliever medication as-needed [1, 2]. Over the last decade, long-acting $\beta_{2}$-agonists (LABA) have become widely used as regular maintenance treatment in conjunction with inhaled corticosteroids (ICS) [3, 4]. Rapidacting $\beta_{2}$-agonists, such as salbutamol and terbutaline, are established reliever medications, but have a relatively short duration of bronchodilator effect.

Formoterol is a unique $\beta_{2}$-agonist, being both rapid and long acting $[5,6]$. In mild, moderate and severe persistent asthma, the use of formoterol as maintenance therapy or asneeded, has resulted in improvements in asthma control [7-9]. The 3-month study by TATTERSFIELD et al. [9] demonstrated that the use of formoterol as reliever medication reduced exacerbations compared with terbutaline, without compromising safety in patients with moderate-persistent asthma who used frequent doses of reliever medication despite regular ICS. However, that study raised questions as to whether these observations of safety and efficacy could be extended to a wider population of patients with asthma.

The safety and efficacy of $\beta_{2}$-agonists may vary according to age, severity of disease, and concomitant medication [10].

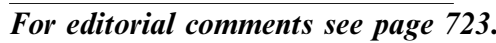

With respect to formoterol, a key question is safety and efficacy when used as-needed in conjunction with regular LABA. The safety of formoterol as-needed, in the absence of ICS, is also of relevance given the potential for LABA to mask an underlying deterioration in airway inflammation [11].

This 6-month "real-life" study was designed to assess the safety and effectiveness of formoterol as reliever medication, compared with the most widely used reliever therapy, salbutamol, in asthmatics over a wide age range, with different degrees of asthma severity and receiving a variety of other maintenance medications. As safety was the primary focus and in order to mimic clinical practice, the study was run open-label to allow each of the participating countries to compare formoterol with salbutamol by the most appropriate inhaler. Data collected by the patient and investigator focussed on adverse events (AE)s and exacerbations whereas collection of other efficacy data was minimised.

\section{Methods}

\section{Study subjects}

Outpatients from general practice and specialist centres, 
aged $\geqslant 6$ yrs, with a clinical diagnosis of asthma and using, or candidates for receiving, a $\beta_{2}$-agonist as reliever medication, were eligible. Females who were pregnant, breastfeeding or not using an acceptable method of contraception were excluded. To mimic a normal prescribing situation, patients with concomitant cardiovascular diseases were included at the discretion of the treating physician. Prescribing information indicated a need for caution in patients with thyrotoxicosis, ischaemic heart disease, tachyarrhythmias, severe heart failure or prolonged Q-T interval corrected for heart rate.

Written informed consent was obtained from all adult patients and from the parent or legal guardian of all children. Written or oral consent was obtained from all children. The open, randomised, parallel-group study was carried out at 1,139 centres in 24 countries. Approval was obtained from regulatory agencies and ethics committees at all centres.

\section{Study design}

The primary safety variables were asthma-related and nonasthma-related serious AEs (SAE)s and discontinuations due to AEs (DAE)s. An SAE was any event causing death, any life-threatening condition, hospitalisation or prolongation of hospitalisation, persistent or significant disability or congenital abnormality. DAEs included both nonserious and serious AEs. Asthma-related events were events including "asthma aggravated symptoms" or "asthma not otherwise specified". Cardiovascular-related events were events including symptoms in system organ class cardiac disorders or sudden cardiac death.

The primary efficacy variable was time to first exacerbation. An exacerbation was defined by one or more of the following: 1) any increase in maintenance asthma medication; 2) a course of oral corticosteroids lasting $\geqslant 5$ days; 3 ) emergency treatment with nebulised $\beta_{2}$-agonist or corticosteroid injection; or 4) hospitalisation, all due to deterioration of asthma. A severe exacerbation was defined as any of the events (2-4).

At entry, patients were randomised in chronological order at each site, according to a computer-generated code, and treatment communicated via code envelope. Patients were assigned to one of two treatment as-needed regimens, i.e.

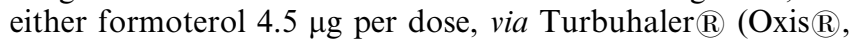
AstraZeneca, Södertälje, Sweden), or salbutamol $200 \mu \mathrm{g}$ per dose via pressurised metered dose inhaler (pMDI) or equivalent dose via dry powder inhaler (DPI). Eighteen countries used salbutamol via $\mathrm{pMDI}$, one via Diskhaler $\mathbb{R}$ $\left(200 \mu \mathrm{g}\right.$ per dose; Ventolin ${ }^{\mathrm{TM}}$, GlaxoSmithKline, Uxbridge, $\mathrm{UK})$, two via Diskus $\AA\left(200 \mu \mathrm{g}\right.$ per dose; Ventolin ${ }^{\mathrm{TM}}$, GlaxoSmithKline, Uxbridge, UK), and three via Turbuha-

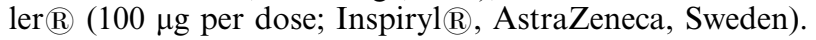

The open-label design allowed each of the 24 participating

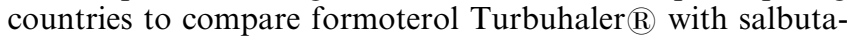
mol by the most appropriate inhaler. Formoterol $4.5 \mu \mathrm{g}$ via

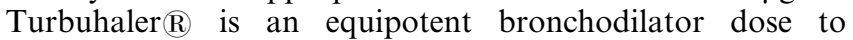
salbutamol $200 \mu \mathrm{g}$ via pMDI [12-14], which was selected as the comparator in 18 countries. In six countries salbutamol was administered via DPIs ("DPI countries") at a dose equivalent to $200 \mu \mathrm{g}$ via pMDI [15]. The use of doubledummy placebo inhalers to blind the study was considered to pose an unacceptable risk that patients in need of reliever medication during an acute attack could inadvertently use a placebo.

Patients attended the clinic at entry to the study and after 1, 3 and 6 months of treatment. Asthma maintenance treatment was recorded at entry and at the final visit. During the study, the investigators could change the maintenance treatment according to their clinical judgment. Patients were instructed to contact the investigator if their use of reliever medication exceeded 12 inhalations per day in adults and eight inhalations per day in children. Patients on regular treatment with a LABA (formoterol or salmeterol) were instructed to contact the investigator if any of the following occurred: 1) daily use of the study medication exceeded 10 and six inhalations in adults and children, respectively, if using regular treatment with formoterol $4.5 \mu \mathrm{g}$ b.i.d.; 2) eight and four inhalations in adults and children, respectively, if using regular treatment with formoterol $9 \mu \mathrm{g}$ b.i.d. or salmeterol $50 \mu \mathrm{g}$ b.i.d.; and 3) four inhalations in adults using either formoterol $18 \mu \mathrm{g}$ b.i.d. or salmeterol $100 \mu \mathrm{g}$ b.i.d. The investigator could then decide on appropriate action.

The patient or parent/legal guardian filled in a notebook distributed to each patient at entry to the study. Any unscheduled healthcare contacts due to asthma, the number of days incapacity due to asthma, and changes in concomitant asthma medication were recorded in the notebook for the entire 6 months. Patients were contacted by telephone to remind them to record daily symptoms and use of study medication during the 2 weeks preceding each scheduled clinic visit.

At each clinic visit, the investigator recorded spontaneously reported and/or observed AEs, including deterioration of any pre-existing medical condition, such as asthma. The number, duration and first occurrence of hospitalisations, the number and first occurrence of emergency treatments, courses of oral corticosteroids, and increases in asthma maintenance medication, and the number of days on which the patient was incapable of performing normal activities were recorded. In addition, over the previous 2 weeks, the total number of inhalations of as-needed study medication and the total number of days with asthma symptoms were recorded. At visit four or at discontinuation from the study, additional information on AEs was collected by means of a standard question "Have you (Has your child) had any health problems since visit one?"

\section{Analysis}

The primary purpose of the study was to examine the safety of formoterol Turbuhaler $(\mathbb{R}$ as-needed and 15,000 patients (7,500 per group) was considered to be an appropriate number for the study to be able to draw conclusions about safety. This meant that for events that occurred in $1 \%$ of the patients, a true odds ratio between the two treatment groups of 1.7 could be detected with $95 \%$ probability. This assumed a significance level of $5 \%$ and a two-sided alternative hypothesis.

The primary safety variables were asthma-related and nonasthma-related SAEs and DAEs. All events were characterised on a preferred term level, counting patients only once for a particular AE, even if the subject experienced multiple occurrences of that AE during the treatment period. The numbers of patients experiencing at least one AE, SAE, DAE or subcategory thereof were compared between the treatment groups using a Chi-squared test. However, in the safety evaluation, p-values were used as flags to indicate possible findings. The overall evaluation of safety was based on all aspects of AEs, not just the primary variables.

Time to first exacerbation was analysed using a Cox proportional hazards model adjusting for treatment, asthma medication level at baseline, age and geographical region. The average use of study drug per day and the percentage of days with asthma symptoms were compared between treatments using a Linear Mixed Effects Model adjusting for treatment, 
period and interaction treatment by period. The distribution of asthma medication levels at end of the study was compared using a Generalised Linear Model (proportional odds) adjusting for treatment and baseline asthma medication level. The number of days when subjects were unable to conduct normal activities due to asthma was compared using an analysis of variance model with treatment as factor and days in study as a covariate.

A priori defined analyses were performed in patient subgroups classified by age and by asthma medication level at entry. The age categories were children (6-11 yrs), adolescents (12-17 yrs), adults (18-64 yrs) and the elderly ( $>64$ yrs). Asthma severity (intermittent, mild, moderate and severe) was defined by the use of maintenance treatment at entry, classified according to recommendations of the Global Initiative for Asthma (GINA) guidelines (table 1) [16]. Post hoc analyses examined outcomes by regular use of LABA and ICS at entry. Both treatment interactions by strata and treatment differences within strata were investigated.

All analyses were undertaken according to intention to treat. A p-value of $<0.05$ was considered statistically significant. All tests were two-sided (where applicable).

\section{Results}

Of 18,132 patients (aged 4-91 yrs) enrolled, 18,124 were randomised to receive formoterol $(n=9,064)$ or salbutamol $(\mathrm{n}=9,060)$. Randomised patients (formoterol 140, salbutamol 122) who did not receive any study treatment or had no data recorded were not included in the analysis. A total of 1,189 discontinued the study (formoterol: $664(7.3 \%)$, salbutamol: $525(5.8 \%) ; \mathrm{p}<0.001)$ due to the following: 1) lost to follow-up (formoterol: 211 (2.3\%), salbutamol: $204(2.3 \%)$ ); 2) AEs (formoterol: $213(2.4 \%)$, salbutamol: $119(1.3 \%)$ ); 3) eligibility criteria not fulfilled (formoterol: $12(0.1 \%)$, salbutamol: 21 $(0.2 \%))$; or 4$)$ other reasons (formoterol: $228(2.5 \%)$, salbutamol: $181(2.0 \%))$. High numbers of patients completed the 6-month study (formoterol: $8260(93 \%)$, salbutamol: 8413 $(94 \%))$ and the mean treatment duration was comparable between the groups (formoterol: 173 versus salbutamol: 175 days).

Demographical data were well balanced between the treatment groups (table 1). At entry, $76 \%$ of the patients were using ICS (budesonide $n=6385$; fluticasone $n=4,365$; beclomethasone $n=2,876$; other ICS $n=58$ ) at a mean daily dose (budesonide equivalents; $400 \mu \mathrm{g}$ budesonide $=250 \mu \mathrm{g}$ fluticasone $=500 \mu \mathrm{g}$ beclomethasone) in the formoterol group of $753 \mu \mathrm{g}$ (range: $40-6,400 \mu \mathrm{g})$ versus $763 \mu \mathrm{g}(40-6,400 \mu \mathrm{g})$ in the salbutamol group. Regular LABA was used by $31 \%$ of patients $(30 \%$ with and $1 \%$ without regular ICS (formoterol $\mathrm{n}=2,267$; salmeterol $\mathrm{n}=3,420)$ ). Age groups and asthma medication levels at entry are shown in table 1. Amongst the salbutamol group, devices were: pMDI $200 \mu \mathrm{g} \mathrm{n}=6,426$; Turbuhaler $\mathbb{R} \quad 100 \mu \mathrm{g} n=1,186 ;$ Diskus $\mathbb{R} \quad 200 \mu \mathrm{g} \quad \mathrm{n}=795$; Diskhaler(R) $200 \mu \mathrm{g} \mathrm{n}=531$.

\section{Safety}

There were no significant differences in the number of patients reporting AEs between the treatment groups. In the formoterol and salbutamol groups $3,734(42 \%)$ and 3,775 $(42 \%)$ patients respectively, experienced at least one $\mathrm{AE}$ (table 2). The most frequently reported events are shown in figure 1a. Asthma-related AEs occurred significantly less frequently in the formoterol group (1,098 patients, $12.3 \%$ versus salbutamol 1,206, $13.5 \%$; $\mathrm{p}=0.018$ ). Among the nonasthma-related AEs, statistically significant differences were found for headache (formoterol 153, 1.7\% versus 112, 1.3\%; $p=0.011$ ), tremor (formoterol $62,0.7 \%$ versus $27,0.3 \%$; $\mathrm{p}<0.001$ ), depression (formoterol $64,0.7 \%$ versus $40,0.4 \%$; $\mathrm{p}=0.018$ ), anxiety (formoterol $44,0.5 \%$ versus $25,0.3 \%$; $\mathrm{p}=0.021$ ) and allergic rhinitis (formoterol $36,0.4 \%$ versus 55 , $0.6 \% ; \mathrm{p}=0.047)$. However, no overall difference between

Table 1.-Demographics and characteristics of the study population

\begin{tabular}{|c|c|c|c|}
\hline Characteristic & Formoterol & Salbutamol & Total \\
\hline Subjects $n$ & 9064 & 9060 & 18124 \\
\hline Gender $\%$ female & 57 & 58 & 57 \\
\hline Race Caucasian/Oriental/Other $\mathrm{n}$ & $6915 / 1438 / 711$ & $6902 / 1428 / 730$ & $13817 / 2866 / 1441$ \\
\hline Age yrs mean (range) & $39(5-91)$ & $39(4-91)$ & $39(4-91)$ \\
\hline \multicolumn{4}{|l|}{ Age groups } \\
\hline Children $\leqslant 11$ yrs & 847 & 849 & $1696(9 \%)$ \\
\hline Adolescents $12-17$ yrs & 790 & 804 & $1594(9 \%)$ \\
\hline Adults $18-64$ yrs & 6526 & 6468 & $12994(72 \%)$ \\
\hline Elderly $\geqslant 65$ yrs & 901 & 939 & $1840(10 \%)$ \\
\hline \multicolumn{4}{|c|}{ Severity judged by asthma medication levels } \\
\hline Intermittent & 1427 & 1396 & $2823(16 \%)$ \\
\hline Mild & 3178 & 3135 & $6313(35 \%)$ \\
\hline Moderate & 3127 & 3154 & $6281(35 \%)$ \\
\hline Severe & 1332 & 1375 & $2707(15 \%)$ \\
\hline \multicolumn{4}{|l|}{ Maintenance treatment at entry } \\
\hline ICS & 6877 & 6907 & $13784(76 \%)$ \\
\hline LABA & 2782 & 2905 & $5687(31 \%)$ \\
\hline Leukotriene modifiers & 830 & 843 & $1673(9 \%)$ \\
\hline Cromones & 220 & 204 & $424(2 \%)$ \\
\hline Xanthines, oral $\beta_{2}$-agonists & 1131 & 1234 & $2365(13 \%)$ \\
\hline Oral corticosteroids & 391 & 389 & $780(4 \%)$ \\
\hline Others & 921 & 940 & $1861(10 \%)$ \\
\hline
\end{tabular}

\#: Intermittent: no maintenance treatment; mild: inhaled corticosteroids (ICS) $<500 \mu \mathrm{g} \cdot \mathrm{day}^{-1}\left(<400 \mu \mathrm{g} \cdot \mathrm{day}^{-1}\right.$ in children) or a regular long-acting $\beta_{2}-$ agonist (LABA), cromone, theophylline or leukotriene modifier; moderate: ICS alone any dose $\geqslant 500 \mu \mathrm{g} \cdot \mathrm{day}^{-1}\left(\geqslant 400 \mu \mathrm{g} \cdot \mathrm{day}^{-1}\right.$ in children), or ICS $500-800 \mu \mathrm{g} \cdot$ day $^{-1}\left(400-800 \mu \mathrm{g} \cdot\right.$ day $^{-1}$ in children) in combination with LABA, theophylline or leukotriene modifier; severe: ICS $>800 \mu \mathrm{g} \cdot \mathrm{day}^{-1}$ in combination with LABA, theophylline, leukotriene modifier, or oral corticosteroids [16]. 
Table 2. - Number of patients reporting adverse events $(A E) s$, serious AEs (SAE)s and discontinuations due to AEs

\begin{tabular}{|c|c|c|c|c|c|}
\hline & \multicolumn{2}{|c|}{ Formoterol } & \multicolumn{2}{|c|}{ Salbutamol } & \multirow[t]{2}{*}{ p-value } \\
\hline & $\mathrm{n}$ & $\%$ & $\mathrm{n}$ & $\%$ & \\
\hline Subjects & 8924 & & 8938 & & \\
\hline \multicolumn{6}{|l|}{ AEs } \\
\hline Total AEs & 3734 & 42.0 & 3775 & 42.0 & 0.59 \\
\hline Asthma-related AE & 1097 & 12.3 & 1205 & 13.5 & 0.018 \\
\hline Nonasthma-related AE & 2636 & 29.5 & 2569 & 28.7 & 0.24 \\
\hline Cardiovascular-related AE & 119 & 1.3 & 107 & 1.2 & 0.46 \\
\hline \multicolumn{6}{|l|}{ Serious AEs } \\
\hline Total serious AEs & 278 & 3.1 & 299 & 3.3 & 0.38 \\
\hline Deaths & 13 & 0.1 & 11 & 0.1 & 0.68 \\
\hline Asthma-related SAE & 108 & 1.2 & 121 & 1.4 & 0.39 \\
\hline Nonasthma-related SAE & 170 & 1.9 & 178 & 2.0 & 0.68 \\
\hline Cardiovascular-related SAE & 23 & 0.3 & 35 & 0.4 & 0.15 \\
\hline \multicolumn{6}{|l|}{ Discontinuations due to AEs } \\
\hline Total discontinuations & 213 & 2.4 & 119 & 1.3 & $<0.001$ \\
\hline Due to SAE & 40 & 0.4 & 37 & 0.4 & 0.73 \\
\hline Due to non-serious AE & 173 & 1.9 & 82 & 0.9 & $<0.001$ \\
\hline Due to asthma-related AE & 89 & 1.0 & 48 & 0.5 & $<0.001$ \\
\hline Due to nonasthma-related $\mathrm{AE}$ & 124 & 1.4 & 71 & 0.8 & $<0.001$ \\
\hline
\end{tabular}

treatments was seen for the total nonasthma-related AEs or for cardiovascular-related AEs.

In all, 305 SAEs occurred in 278 patients (3.1\%) using formoterol, including 13 deaths $(0.1 \%)$, compared with 327 SAEs in 299 patients $(3.3 \%)$ using salbutamol, including 11 deaths $(0.1 \%)$ (table 2$)$. There were five asthma-related deaths reported as "asthma aggravated" (formoterol three, salbutamol two) and eleven cardiovascular-related deaths (formoterol five, salbutamol six). The most frequently reported SAEs are shown in figure $1 \mathrm{~b}$. There were no differences between treatments in number of asthma-related SAEs, in number or type of nonasthma-related SAEs, or in number of cardiovascular-related SAEs.

DAEs in the study were few. There were more DAEs in the formoterol group $(213(2.4 \%)$ versus $119(1.3 \%) ; \mathrm{p}<0.001)$ but this difference in DAEs was not due to SAEs $(40,0.4 \%$ formoterol versus $37,0.4 \%$ salbutamol; $\mathrm{p}=0.73$ ) but rather to nonserious AEs $(173,1.9 \%$ formoterol versus 82, $0.9 \%$ salbutamol; $\mathrm{p}<0.001)$. The number of asthma-related DAEs was significantly higher with formoterol $(89,1.0 \%$ versus 48 , $0.5 \% ; \mathrm{p}<0.001)$. A statistically significant treatment interaction for asthma-related DAEs by inhaler type (countries with DPI or $\mathrm{pMDI}$ ) was present $(\mathrm{p}=0.029)$. In the six DPI countries $(n=5,056)$ the incidence of asthma-related DAEs was similar with formoterol and salbutamol $(28,1.1 \%$ versus $24,1.0 \%$; $\mathrm{p}=0.61)$, whereas a significant treatment difference was seen in the 18 pMDI countries $(n=12,806)(61,1.0 \%$ versus $24,0.4 \%$; $\mathrm{p}<0.001$ ). However, also within the pMDI countries there was a large variation, indicating that the increased rate of asthmarelated DAEs in a few countries was not representative of the whole study population.

There were significantly more nonasthma-related DAEs in the formoterol group (124, 1.4\% versus $71,0.8 \% ; \mathrm{p}<0.001)$. No treatment interaction by inhaler type was seen $(\mathrm{p}=0.86)$, with about the same increase in DPI countries (formoterol 48, $1.9 \%$ versus $281.1 \%$ ) as in pMDI countries (formoterol 76, $1.2 \%$ versus $43,0.7 \%$ ). Among symptoms, statistically significant differences were found for tremor (formoterol 19, $0.2 \%$ versus six, $0.1 \% ; \mathrm{p}=0.009$ ), headache (formoterol 14 , $0.2 \%$ versus three, $0.1 \% ; \mathrm{p}=0.008$ ) and tachycardia (formoterol nine, $0.1 \%$ versus two, $0.1 \%$; $=0.034$ ).
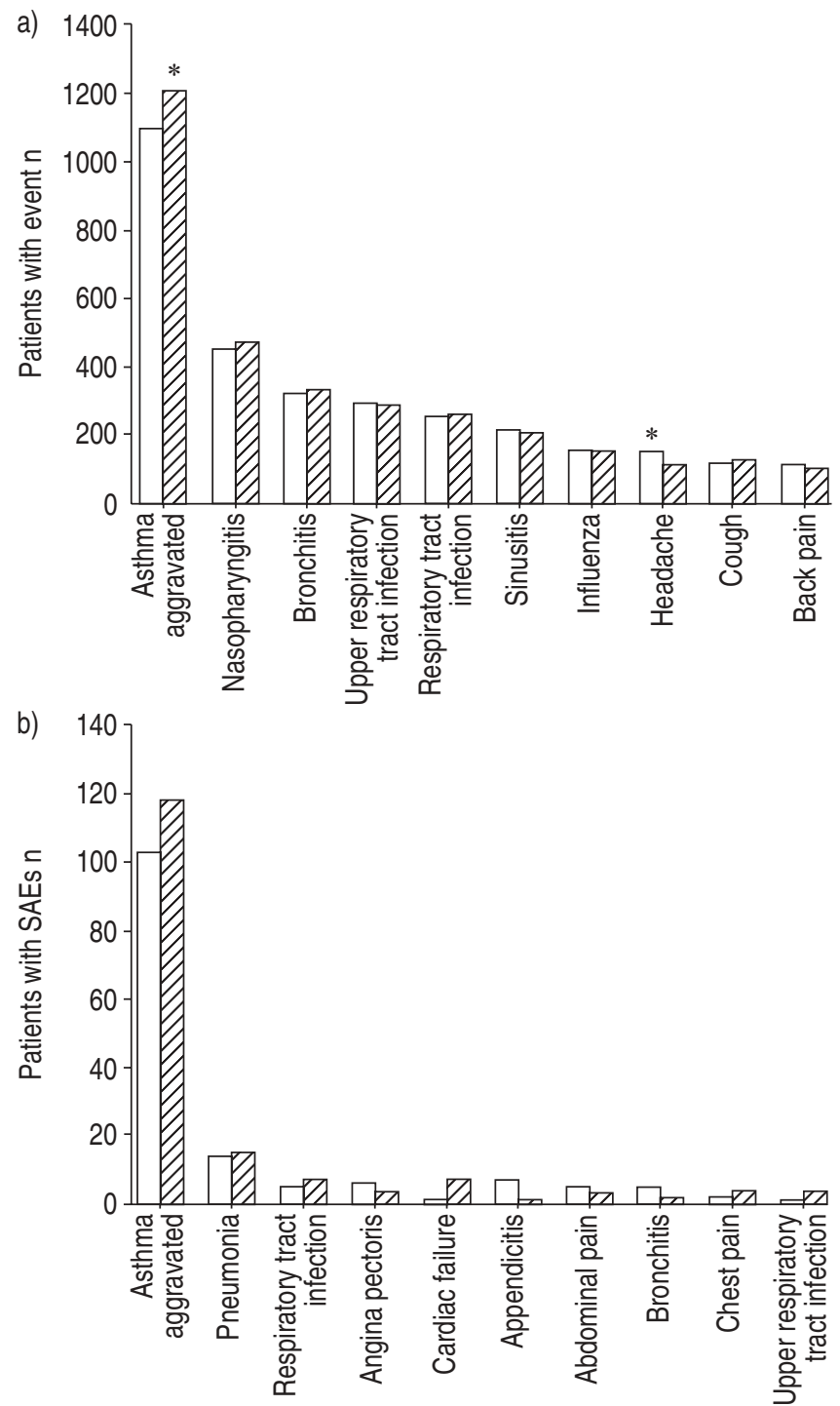

Fig. 1. - a) Most frequent adverse events and b) most frequent serious adverse events (SAE)s by preferred term reported in patients using formoterol $(\square)$ or salbutamol $(\mathbb{Z})$ as reliever medication. *: $\mathrm{p}<0.05$ formoterol versus salbutamol.

There were no differences between the study treatments for safety variables related to age, asthma medication levels, or concomitant ICS or LABA treatment (table 3). In general, $\mathrm{AE}$ and $\mathrm{SAE}$ rates increased with age and asthma medication level, but overall the rates were low and evenly distributed between the treatment groups. Rates of DAEs increased with age, and the incidence was higher with formoterol in all subgroups.

\section{Efficacy}

Fewer patients using formoterol experienced at least one exacerbation of any category (2,549 (28.6\%) versus 2,893 $(32.4 \%))$, or at least one severe exacerbation $(1,181(13.2 \%)$ versus $1,343(15.0 \%))$. The time to first asthma exacerbation of any category (primary efficacy variable) was significantly longer in the formoterol group compared with the salbutamol group (fig. 2a). The hazard ratios (HR) between treatment groups showed a $14 \%$ reduction in relative risk for a first 
Table 3. - Analysis of subgroups

\begin{tabular}{|c|c|c|c|c|c|c|c|}
\hline \multirow[t]{2}{*}{ Subgroup } & \multicolumn{2}{|c|}{ SAE } & \multicolumn{2}{|c|}{ DAE } & \multicolumn{3}{|c|}{ Exacerbations (any category) } \\
\hline & Form & Salb & Form & Salb & Form & Salb & $\begin{array}{c}\text { Hazard ratio } \\
\text { Form/Salb }(95 \% \mathrm{CI})\end{array}$ \\
\hline \multicolumn{8}{|l|}{ Age groups } \\
\hline Children & $19(2.3)$ & $14(1.7)$ & $5(0.6)$ & $1(0.1)$ & 32.4 & 35.0 & $0.904(0.766-1.067)$ \\
\hline Adolescents & $16(2.0)$ & $16(2.0)$ & $14(1.8)$ & $6(0.8)$ & 23.6 & 26.1 & $0.892(0.731-1.087)$ \\
\hline Adults & $182(2.8)$ & $205(3.2)$ & $151(2.4)$ & $87(1.4)$ & 29.1 & 33.1 & $0.857^{\#}(0.806-0.912)$ \\
\hline Elderly & $61(6.8)$ & $64(6.9)$ & $43(4.8)$ & $25(2.7)$ & 25.2 & 30.0 & $0.815^{\#}(0.684-0.972)$ \\
\hline \multicolumn{8}{|c|}{ Severity judged by asthma medication levels } \\
\hline Intermittent & $25(1.8)$ & $18(1.3)$ & $30(2.2)$ & $14(1.0)$ & 24.9 & 25.7 & $0.971(0.837-1.126)$ \\
\hline Mild & $91(2.9)$ & $77(2.5)$ & 59 (1.9) & $34(1.1)$ & 27.3 & 31.1 & $0.854^{\#}(0.779-0.937)$ \\
\hline Moderate & $92(3.0)$ & $108(3.5)$ & $69(2.2)$ & $50(1.6)$ & 28.1 & 32.1 & $0.853^{\#}(0.779-0.934)$ \\
\hline Severe & $70(5.3)$ & $96(7.1)$ & $55(4.2)$ & $21(1.5)$ & 36.7 & 42.6 & $0.824^{\#}(0.730-0.930)$ \\
\hline \multicolumn{8}{|c|}{ Maintenance medication type } \\
\hline LABA & $111(4.0)$ & $145(5.0)$ & $75(2.7)$ & $43(1.5)$ & 32.3 & 35.5 & $0.891^{\#}(0.815-0.975)$ \\
\hline No LABA & $167(2.7)$ & $154(2.5)$ & $138(2.2)$ & $76(1.3)$ & 26.9 & 30.9 & $0.849^{\#}(0.795-0.907)$ \\
\hline ICS & $229(3.4)$ & $257(3.8)$ & $172(2.5)$ & $93(1.4)$ & 29.5 & 33.8 & $0.850^{\#}(0.801-0.903)$ \\
\hline No ICS & $49(2.3)$ & $42(2.0)$ & 41 (1.9) & $26(1.2)$ & 25.6 & 27.8 & $0.906(0.806-1.017)$ \\
\hline
\end{tabular}

Data are presented as n (\%) unless otherwise stated. SAE: serious adverse events; DAE: discontinuations due to adverse events; Form: Formoterol; Salb: Salbutamol; 95\% CI: 95\% confidence interval; LABA: long-acting $\beta_{2}$-agonist; ICS: inhaled corticosteroids. ${ }^{\#}$ : significant treatment difference. ๆ: Defined in accordance to Global Initiative for Asthma guidelines as a surrogate for asthma severity (see table 1 footnote for definitions and subgroup sizes).
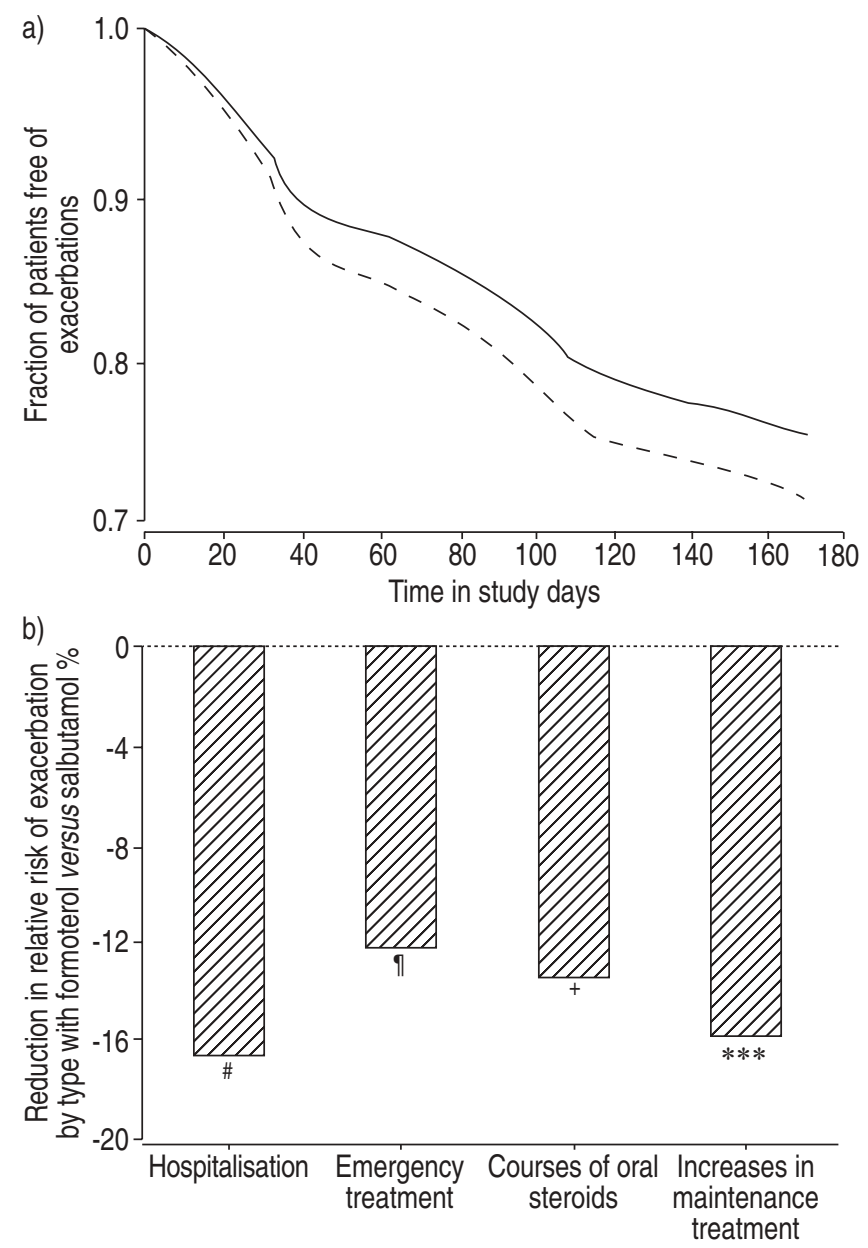

Fig. 2.-a) Kaplan-Meier survival curve showing the percentage of patients who did not have an exacerbation of any category $(\mathrm{p}<0.001)$. -: formoterol; - - -: salbutamol. b) The reduction in relative risk with respect to first exacerbation with formoterol versus salbutamol by category. ${ }^{\#}$ : $\mathrm{p}=0.141 ;{ }^{\bullet}: \mathrm{p}=0.026{ }^{+}: \mathrm{p}=0.002 ; * * *: \mathrm{p}<0.001$. exacerbation of any category (HR 0.861, 95\% confidence interval $(95 \% \mathrm{CI})$ : $0.817-0.908 ; \mathrm{p}<0.001)$, and $12 \%$ reduction for first severe exacerbation in the formoterol group $(0.880$, $0.813-0.951 ; \mathrm{p}=0.0013)$. The numbers of patients who experienced at least one exacerbation by subcategory were the following: 1) hospitalisations (formoterol $111(1.2 \%)$ versus $134(1.5 \%)$ ); 2) emergency treatments (formoterol 616 $(6.9 \%)$ versus $701(7.8 \%))$; 3 ) courses of oral corticosteroids (formoterol $830(9.3 \%)$ versus $959(10.7 \%)$ ); and 4) increases in maintenance treatment (formoterol 1,995 (22.4\%) versus 2,335 $(26.1 \%))$. Compared with salbutamol, the relative risks of all types of asthma exacerbations were reduced by $12-16 \%$ with formoterol. The difference was significant in all cases, except for hospitalisations where the overall incidence was low (fig. 2b). No difference was found in the number of hospital days (formoterol: 0.090, salbutamol: 0.114 days per patient).

Patients in each age group and in each level of baseline asthma medication had longer times to first exacerbation with formoterol compared with salbutamol (table 3). Risk reductions with as-needed formoterol increased both with increasing age and with increasing baseline medication level, but there was no significant treatment interaction (fig. 3). No treatment interaction was seen by use of ICS or by use of LABA (table 3 ).

During the study, the use of reliever medication in the overall population decreased with both treatments, with a significant difference in favour of formoterol at each time point (table 4). The differential effect with formoterol in the final treatment period, expressed as a percentage of use in the salbutamol group, indicated a $16 \%$ reduction. Children and adolescents used little reliever medication throughout the study and to a similar extent in both treatment groups. However, in adults and elderly patients whose requirement for reliever therapy was higher, formoterol significantly reduced the need for reliever treatment (fig. $4 \mathrm{a}-\mathrm{c}$ ). Reliever use was significantly reduced with formoterol for all asthma medication levels (fig. 4e-h). Compared with salbutamol, formoterol as-needed was used less than salbutamol independent of use of concomitant ICS and LABA (fig. 4i-1).

The percentage of days with asthma symptoms decreased in both groups during the study. Patients using formoterol had a significant reduction in days with asthma symptoms versus 

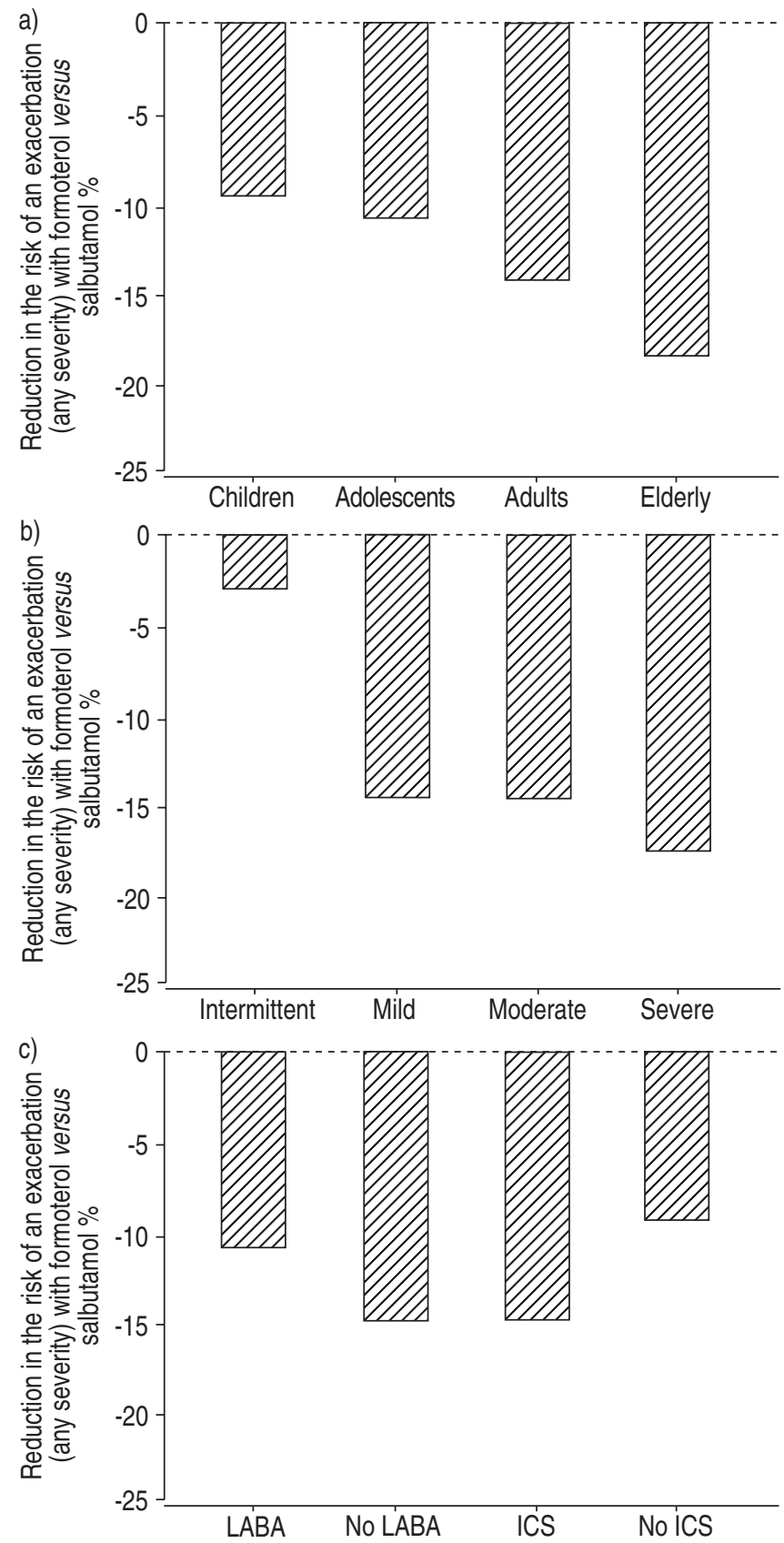

Fig. 3. - Reduction in the relative risks of having a first asthma exacerbation with formoterol versus salbutamol, in subgroups of patients by a) age, b) asthma medication level and c) maintenance therapy type. LABA: long-acting $\beta_{2}$-agonist; ICS: inhaled corticosteroids.

salbutamol in all periods (table 4). The frequency of days when patients were unable to perform normal activities due to their asthma was similar in both groups (formoterol 2.5; salbutamol 2.8 days $\cdot \mathrm{yr}^{-1}$; $\left.\mathrm{p}=0.083\right)$.

The majority of patients ( $79 \%$ in both groups) had the same asthma medication level (table 1) at entry and at the end of the study. Decreases were more frequent in those using formoterol, $6.8 \%$ had an increase and $14.4 \%$ a decrease, than those using salbutamol, 7.8\% had an increase and $13.1 \%$ a decrease $(\mathrm{p}<0.001$ formaterol versus salbutamol). Mean doses of ICS were similar between patients using ICS at visit one and patients using ICS at visit four in the formoterol group (750 and $753 \mu \mathrm{g} \cdot \mathrm{day}^{-1}$ budesonide equivalents) and the salbutamol group (759 and $766 \mu \mathrm{g} \cdot \mathrm{day}^{-1}$ budesonide equivalents).

\section{Discussion}

This international real-life study performed in a widely diverse population of $>18,000$ asthmatics showed that using the rapid and long-acting $\beta_{2}$ aganist formoterol as reliever medication was as safe as using the rapid and short-acting $\beta_{2^{-}}$ agonist salbutamol. In addition, use of formoterol as reliever medication resulted in a prolonged time to a first asthma exacerbation and reduced medication requirements.

The real-life study design had several unique features to maximise recruitment of a diverse population and to approach normal clinical practice. These included minimal entry criteria, no run-in period, and no lung function or compliance measurements. Daily records of symptoms and reliever use were only collected for 2 weeks before each postrandomisation visit. Classification of patient's asthma severity was based only on levels of maintenance treatment at entry in relation to GINA guidelines [16], but asthma control was not assessed before randomisation. The salbutamol dose for comparison, $200 \mu \mathrm{g}$ via pMDI, was selected to provide equivalent bronchodilator effect to formoterol $4.5 \mu \mathrm{g} v \mathrm{ia}$

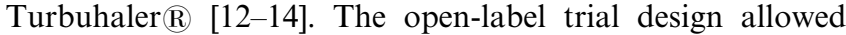
formoterol Turbuhaler to be compared with salbutamol via any delivery device, especially pMDI, which is the most widely used delivery device for reliever medication. Blinding using double-dummy placebo relief medication was excluded for safety reasons. An open design was deemed appropriate, as the primary study focus was safety.

The use of formoterol as reliever medication was not associated with any increase in AEs, SAEs, cardiovascular side-effects or discontinuations due to SAEs compared with salbutamol. No differences were observed in the incidence of asthma-related and cardiovascular-related deaths. Wellknown side-effects of $\beta_{2}$-agonists, such as headache and tremor, were more frequent in the formoterol group but the difference compared to salbutamol was very small (increased incidence affecting around one in 250 patients). In the salbutamol group, $1.2 \%$ more patients had an asthma-related $\mathrm{AE}$ and $3.8 \%$ more patients had asthma exacerbations as defined. In contrast, fewer $(0.5 \%)$ salbutamol patients discontinued the study due to asthma-related AEs. No difference in rates of asthma-related DAEs was found in DPI countries, whereas an unevenly distributed difference was found in the pMDI countries, making it possible that the open study design contributed to this difference in asthmarelated DAEs in favour of salbutamol. As there were no differences in the total numbers of AEs or SAEs, and the difference in DAEs was only due to nonserious AEs, asneeded formoterol can be considered to have a similar safety profile to salbutamol in asthmatic patients.

The current study confirms that formoterol, when used asneeded, reduces exacerbations of asthma as demonstrated previously in a double-blind trial [9]. Furthermore, in the present study formoterol as-needed also reduced exacerbations when added to maintenance LABA. In contrast to several double-blind trials [7-9], only clinical criteria (asthma events) were used to define exacerbations in this real-life study. An obvious limitation of the study was that the investigators were not blinded to treatment and this may have influenced study outcomes, e.g. excessive reliever use or symptoms recorded in the notebook could make the investigator increase maintenance treatment or prescribe an oral steroid course to a greater extent in one or other group depending on expectations or experience. However, relative risks of experiencing severe exacerbations, such as hospitalisation or emergency treatment, were reduced by formoterol as-needed to a similar extent as exacerbations classified by an increase in maintenance therapy or the need for a course of oral steroids. 
Table 4.- Adjusted means and ranges for use of study medication and days with asthma symptoms

\begin{tabular}{|c|c|c|c|c|}
\hline \multirow[t]{2}{*}{ Study period } & \multicolumn{2}{|c|}{ Adjusted means } & \multirow[t]{2}{*}{ Mean difference $(95 \% \mathrm{CI})$} & \multirow[t]{2}{*}{ p-value } \\
\hline & Formoterol & Salbutamol & & \\
\hline \multicolumn{5}{|c|}{ Reliever use doses per day (range) } \\
\hline Period 1 & $1.36(0-13.1)$ & $1.57(0-20.0)$ & $-0.21(-0.26-0.16)$ & $<0.001$ \\
\hline Period 2 & $1.29(0-16.5)$ & $1.50(0-21.4)$ & $-0.21(-0.26-0.16)$ & $<0.001$ \\
\hline Period 3 & $1.23(0-16.5)$ & $1.46(0-20.7)$ & $-0.22(-0.27-0.17)$ & $<0.001$ \\
\hline \multicolumn{5}{|c|}{ Percentage of days with asthma symptoms (range) } \\
\hline Period 1 & $42.35(0-100)$ & $44.37(0-100)$ & $-2.02(-3.16-0.87)$ & $<0.001$ \\
\hline Period 2 & $41.26(0-100)$ & $42.55(0-100)$ & $-1.29(-2.44-0.14)$ & 0.029 \\
\hline Period 3 & $39.49(0-100)$ & $41.20(0-100)$ & $-1.71(-2.87-0.55)$ & 0.004 \\
\hline
\end{tabular}

Data were recorded during the last 2 weeks of each study period; Period 1: end of month 1; period 2: end of month 3; period 3: end of month 6. 95\% CI: $95 \%$ confidence interval.
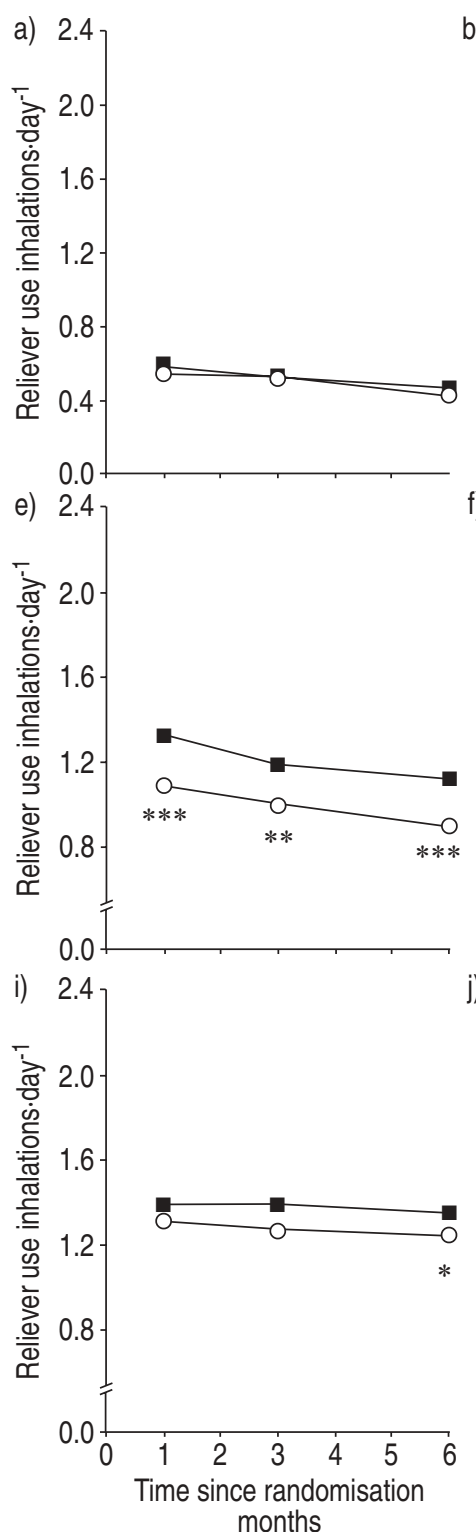
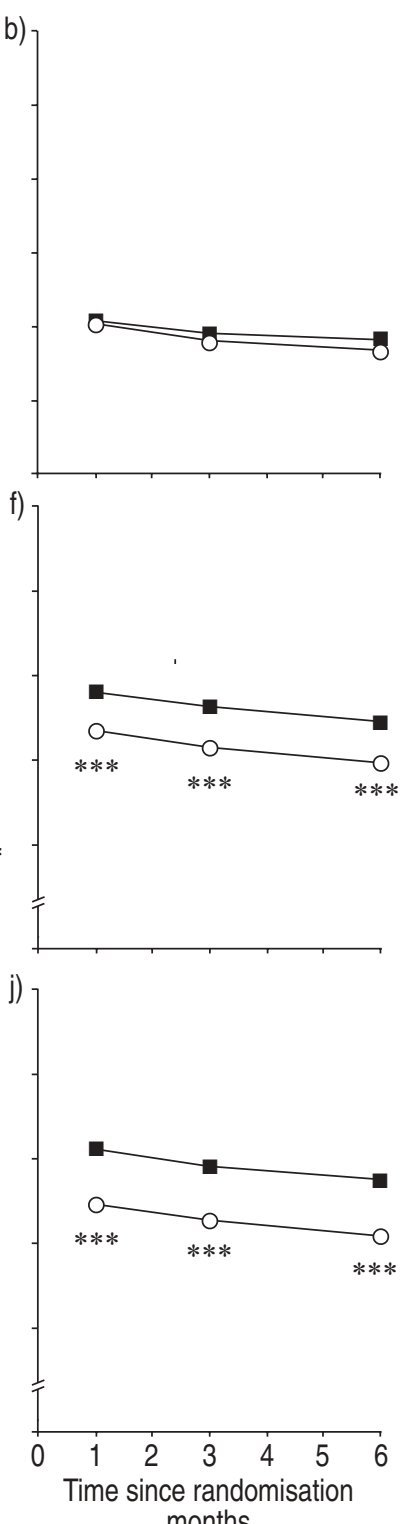
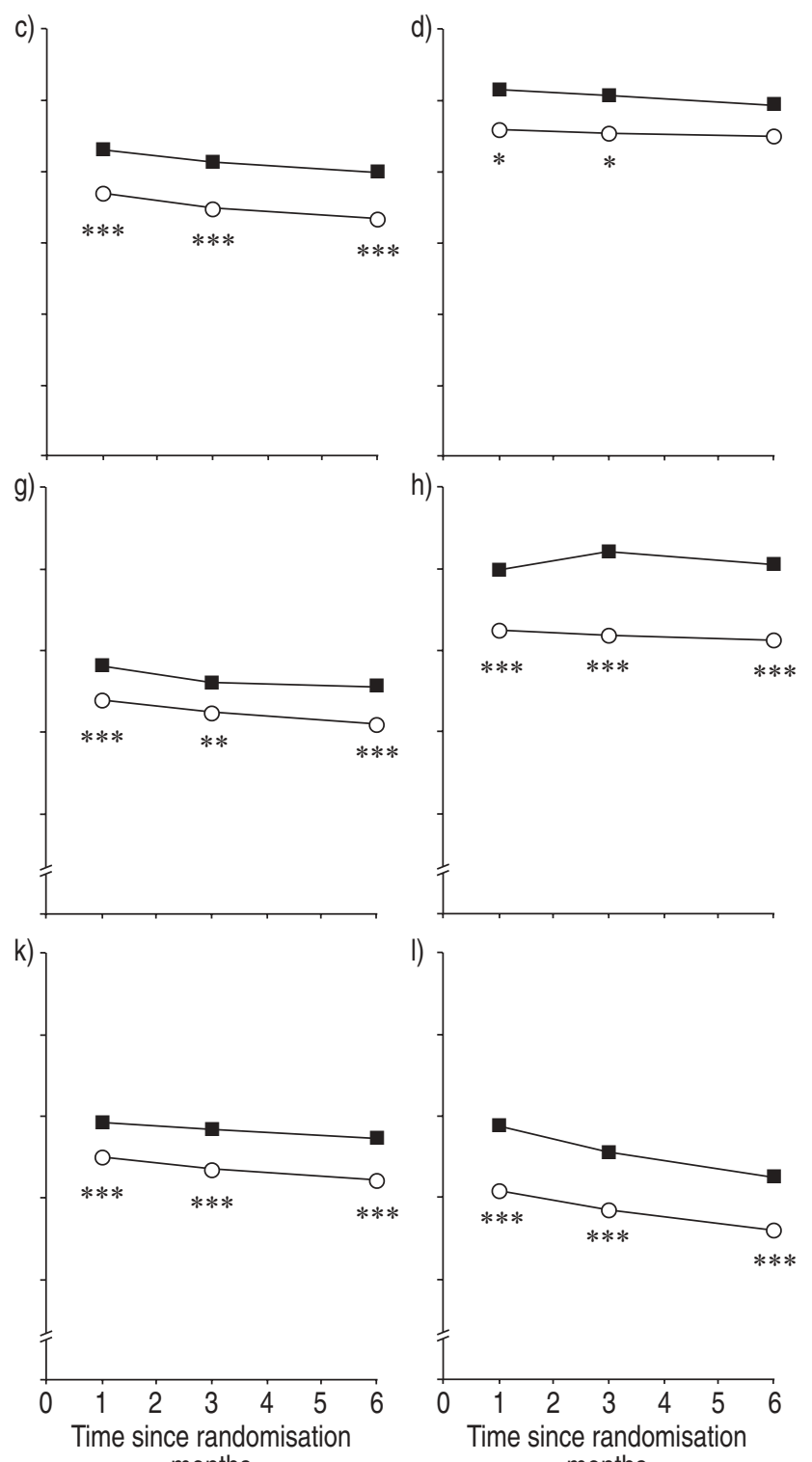

months
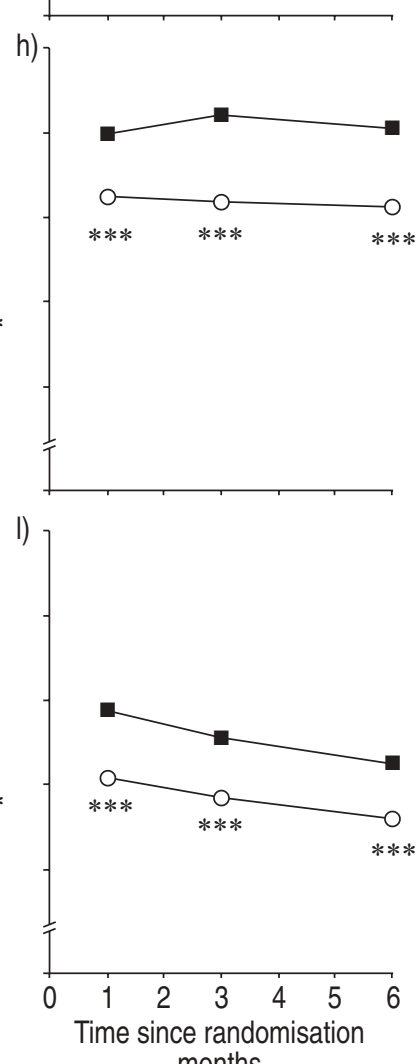

Fig. 4.-Use of study medication over time in the formoterol ( $\bigcirc$ ) and salbutamol ( $\mathbf{a})$ treatment groups stratified by age (children (a), adolescents (b), adults (c), elderly (d)), asthma medication level (intermittent (e), mild (f), moderate (g) severe (h)) and type of maintenance therapy (long-acting $\beta_{2}$-agonist (LABA) (i), No LABA (j), inhaled corticosteroids (ICS) (k), no ICS (l)). *: p<0.05; **: p<0.001; ***: p<0.001 formoterol versus salbutamol. 
Furthermore, whilst increases in maintenance therapy often coincided with scheduled clinic visits, reflecting normal clinical practice, the occurrence of severe exacerbations was not temporally associated with scheduled visits.

The analyses by age and asthma maintenance level were performed in subgroups larger than many previous trials with formoterol [7-9], and are therefore useful additions to the overall analysis. Any differences in safety profiles between formoterol and salbutamol in the subgroups were consistent with the overall findings. There were no signs of loss of asthma control with as-needed formoterol in any subgroup, including patients not using concomitant ICS.

When LABAs were first introduced there were concerns that they could have similar adverse effects to regular use of short-acting inhaled $\beta_{2}$-agonists [17]. However, a large body of clinical studies have established the safety of LABA use, especially in combination with ICS therapy [18-21]. Data from the current study indicate that maintenance use of ICS or LABA do not affect the safety or efficacy profiles of formoterol compared with salbutamol. The subgroup analyses provide evidence of good safety and efficacy of formoterol as-needed versus salbutamol in mild-intermittent to severe-persistent asthma, in all age groups from 6-yr-olds to the elderly and in patients treated with or without maintenance LABA and ICS therapy. These are important findings, since using a rapid and long-acting $\beta_{2}$-agonist, both as reliever and as maintenance therapy, could increase the simplicity and convenience of bronchodilator treatment for many patients.

Asthma guidelines currently advocate stepwise increases in maintenance therapy to control asthma. In this study, clinicians could alter maintenance therapy as judged appropriate. Nevertheless, the increased effectiveness of as-needed formoterol versus salbutamol in reducing all exacerbations, severe exacerbations and achieving greater reductions in maintenance and as-needed therapy, suggests that the choice of reliever therapy may also be important in optimising asthma control.

In conclusion, this real-life study has shown that formoterol as-needed has a similar safety profile to salbutamol, and in this open study its use as a reliever therapy was associated with fewer asthma symptoms and exacerbations.

\footnotetext{
Acknowledgements. The authors would like to thank all the investigators for their active participation in the RELIEF (REal LIfe EFfectiveness

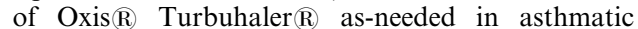
patients) study.
}

\section{References}

1. Global Initiative for Asthma. Global Strategy for Asthma Management and Prevention. National Institutes of Health. National Heart, Lung and Blood Institute, Publication 953659, 1995; 1-176.

2. British Thoracic Society. The British guidelines on asthma management. Thorax 1997; 52: Suppl. 1, 1-21.

3. Rabe KF, Vermeire PA, Soriano JB, Maier WC. Clinical management of asthma in 1999: the Asthma Insights and Reality in Europe (AIRE) study. Eur Respir J 2000; 16: $802-807$.
4. Holgate ST. Therapeutic options for persistent asthma JAMA 2001; 285: 2637-2639.

5. Derom EY, Pauwels RA. Time course of bronchodilating effect of inhaled formoterol, a potent and long acting sympathomimetic. Thorax 1992; 47: 30-33.

6. Ringdal N, Derom E, Wảhlin-Boll E, Pauwels R. Onset and duration of action of single doses of formoterol inhaled via Turbuhaler. Respir Med 1998; 92: 1017-1021.

7. Pauwels RA, Löfdahl C-G, Postma DS, et al. Effect of inhaled formoterol and budesonide on exacerbations of asthma. N Engl J Med 1997; 337: 1405-1411.

8. $\mathrm{O}^{\prime}$ Byrne PM, Barnes PJ, Rodriguez-Roisin R, et al. Low dose inhaled budesonide and formoterol in mild persistent asthma. The OPTIMA randomized trial. Am J Respir Crit Care Med 2001; 164: 1392-1397.

9. Tattersfield AE, Löfdahl CG, Postma DS, et al. Comparison of formoterol and terbutaline for as-needed treatment of asthma: a randomised trial. Lancet 2001; 357: 257-261.

10. Fraser PM, Speizer FE, Waters SD, Doll R, Mann NM. The circumstances preceding death from asthma in young people in 1968 to 1969. Br J Dis Chest 1971; 65: 71-84.

11. McIvor RA, Pizzichini E, Turner MO, Hussack P, Hargreave FE, Sears MR. Potential masking effects of salmeterol on airway inflammation in asthma. Am $J$ Respir Crit Care Med 1998; 158: 924-930.

12. Seberová E, Andersson A. Oxis (formoterol given by Turbuhaler) showed as rapid an onset of action as salbutamol given by a pMDI. Respir Med 2000; 94: 607-611.

13. Rosenborg $\mathrm{J}$, Bengtsson $\mathrm{T}$, Larsson $\mathrm{P}$, Blomgren $\mathrm{A}$, Persson G, Lötvall J. Relative systemic dose potency and tolerability of inhaled formoterol and salbutamol in healthy subjects and asthmatics. Eur J Clin Pharmacol 2000; 56: $363-370$.

14. Rosenborg J, Larsson P, Rott Z, Böcskei C, Poczi M, Juhász G. Relative therapeutic index between inhaled formoterol and salbutamol in asthma patients. Respir Med 2002; 96: $412-417$.

15. Chapman KR, Friberg K, Balter MS, et al. Albuterol via Turbuhaler versus albuterol via pressurized metered-dose inhaler in asthma. Ann Allergy Asthma Immunol 1997; 78: $59-63$.

16. Global Initiative for Asthma. Pocket guide for asthma management and prevention. National Institutes of Health. National Heart, Lung and Blood Institute, Publication 963659B, 1998; 1-29.

17. Sears MR, Taylor DR, Print CG, et al. Regular inhaled beta-agonist treatment in bronchial asthma. Lancet 1990; 336: 1391-1396.

18. Verberne AA, Frost C, Roorda RJ, van der Laag H, Kerrebijn KF. One-year treatment with salmeterol compared with beclomethasone in children with asthma. Am J Respir Crit Care Med 1997; 156: 688-695.

19. Shrewsbury S, Pyke S, Britton M. Meta-analysis of increased dose of inhaled steroid or addition of salmeterol in symptomatic asthma (MIASMA). BMJ 2000; 320: 13681373.

20. Lemanske RF, Sorkness CA, Mauger EA, et al. Inhaled corticosteroid reduction and elimination in patients with persistent asthma receiving salmeterol - A randomized controlled trial. JAMA 2001; 285: 2594-2603.

21. van der Molen T, Postma DS, Turner MO, et al. Effects of the long-acting beta-agonist formoterol on asthma control in asthmatic patients using inhaled corticosteroids. Thorax 1997; 52: 535-539. 